\title{
Mechanical thrombectomy in patients with acute ischemic stroke: a cost-utility analysis
}

\author{
Xuanqian Xie MSc, Anna Lambrinos MSc, Brian Chan MSc, Irfan A. Dhalla MD MSc, \\ Timo Krings MD PhD, Leanne K. Casaubon MD MSc, Cheemun Lum MD, Nancy Sikich MSc, \\ Aditya Bharatha MD, Vitor Mendes Pereira MD MSc, Grant Stotts MD, Gustavo Saposnik MD, \\ Christina O'Callaghan BAppSc, Linda Kelloway RN MN, Michael D. Hill MD MSc
}

\section{Abstract}

Background: The beneficial effects of endovascular treatment with new-generation mechanical thrombectomy devices compared with intravenous thrombolysis alone to treat acute large-artery ischemic stroke have been shown in randomized controlled trials (RCTs). This study aimed to estimate the cost utility of mechanical thrombectomy compared with the established standard of care.

Methods: We developed a Markov decision process analytic model to assess the cost-effectiveness of treatment with mechanical thrombectomy plus intravenous thrombolysis versus treatment with intravenous thrombolysis alone from the public payer perspective in Canada. We conducted comprehensive literature searches to populate model inputs. We estimated the efficacy of mechanical thrombectomy plus intravenous thrombolysis from a meta-analysis of 5 RCTs, and we used data from the Oxford Vascular Study to model long-term clinical outcomes. We calculated incremental cost-effectiveness ratios (ICER) using a 5-year time horizon.

Results: The base case analysis showed the cost and effectiveness of treatment with mechanical thrombectomy plus intravenous thrombolysis to be $\$ 126939$ and 1.484 quality-adjusted life-years (QALYs), respectively, and the cost and effectiveness of treatment with intravenous thrombolysis alone to be $\$ 124419$ and 1.273 QALYs, respectively. The mechanical thrombectomy plus intravenous thrombolysis strategy was associated with an ICER of $\$ 11990$ per QALY gained. Probabilistic sensitivity analysis showed that the probability of treatment with mechanical thrombectomy plus intravenous thrombolysis being cost-effective was $57.5 \%, 89.7 \%$ and $99.6 \%$ at thresholds of $\$ 20000, \$ 50000$ and $\$ 100000$ per QALY gained, respectively. The main factors influencing the ICER were time horizon, extra cost of mechanical thrombectomy treatment and age of the patient.

Interpretation: Mechanical thrombectomy as an adjunct therapy to intravenous thrombolysis is cost-effective compared with treatment with intravenous thrombolysis alone for patients with acute large-artery ischemic stroke.

\section{A}

cute ischemic stroke is caused by occlusion of a cerebral artery. ${ }^{1}$ This condition carries a high burden of disability and death, and an economic burden due to hospitalization, long-term disability and productivity loss. In Canada, 62000 strokes occur per year, and there are more than 400000 stroke survivors who are living with long-term stroke disability. 2,3 About $87 \%$ of strokes are ischemic and $20 \%$ of those are caused by large-vessel occlusion in the internal carotid artery and middle cerebral artery. ${ }^{4}$ Therefore, about 8700 people per year may be eligible for endovascular treatment in Canada.

Hyperacute treatment of acute ischemic stroke includes time-sensitive therapies designed to open the occluded blood vessels to re-establish blood flow. This can be accomplished through either intravenous thrombolysis and/or endovascular treatment via mechanical thrombectomy with retrievable stents and thrombus aspiration. ${ }^{5}$ Before 2015, intravenous thrombolysis was the standard of care for treating acute ischemic stroke. However, intravenous thrombolysis has several limitations, including a narrow therapeutic time window, applicability to only a subset of stroke patients and relative ineffectiveness for stroke resulting from proximal large-artery occlusion or large-clot burden. ${ }^{6}$

Efforts to improve recanalization rates in patients with a large-artery occlusion were explored with intra-arterial therapy and endovascular treatment with first-generation mechanical thrombectomy devices. Although these therapies failed to show clinical benefit in randomized controlled trials (RCTs), ${ }^{7-9}$

Competing interests: See the end of the article.

This article has been peer reviewed.

Correspondence to: Xuanqian Xie, shawn.xie@ hqontario.ca

CMAJ Open 2016. DOI:10.9778/cmajo.20150088 
trials using new-generation mechanical thrombectomy devices (i.e., stent retriever and thromboaspiration) have shown more promising results. A recent systematic review and meta-analysis based on $5 \mathrm{RCTs}^{10-14}$ of new-generation mechanical thrombectomy reported a clinically significant increase in functional independence for patients who were treated with mechanical thrombectomy employing retrievable stents or thromboaspiration devices (with or without intravenous thrombolysis) compared with those treated with intravenous thrombolysis and/or best medical treatment. ${ }^{15}$ These trials were characterized by a triad of very fast treatment, advanced imaging-based patient selection and high rates of early brain reperfusion. This therapy has now been recommended as the new standard of care for acute ischemic stroke due to large-artery occlusion. ${ }^{16} \mathrm{We}$ conducted a cost-utility analysis from the public payer perspective to determine the health economic impact of mechanical thrombectomy for treatment of patients with large-artery acute ischemic stroke in Canada. The cost-utility analysis was requested by Health Quality Ontario to inform its recommendations regarding public funding of mechanical thrombectomy. Health Quality Ontario is a provincial agency with a broad mandate that includes making recommendations about the Government of Ontario's funding of health care services.

\section{Methods}

\section{Overview}

Based on the efficacy determined by $5 \mathrm{RCTs}^{10-14}$ that examined endovascular treatment with new-generation mechanical thrombectomy devices for patients with acute ischemic stroke in a large artery, we developed a decision analytic model to address the cost-effectiveness of this type of treatment. We modelled treatment with mechanical thrombectomy plus intravenous thrombolysis versus intravenous thrombolysis alone as the expected treatments. The mean age of patients ranged from 65 to 71 years of age, and there was an equal proportion of men and women. ${ }^{10-14}$ Patients had occlusion of either an internal carotid artery or middle cerebral artery, and eligibility for mechanical thrombectomy was confirmed by imaging and established clinical criteria. ${ }^{14}$ Patients were functioning independently in the community before the stroke. We based clinical outcomes for the first 90 days on evidence from a systematic review and meta-analysis. ${ }^{15}$ Long-term outcomes (after $3 \mathrm{mo}$ ) were based on data from the Oxford Vascular Study involving a large cohort of patients with stroke in the United Kingdom. ${ }^{17,18}$ We conducted a comprehensive literature search to obtain the most appropriate inputs of health utility and cost for the cost-utility analysis.

\section{The Markov decision process analytic model}

We developed a Markov decision process analytic model to assess the long-term clinical and economic outcomes of treatment with mechanical thrombectomy plus intravenous thrombolysis versus treatment with intravenous thrombolysis alone (Figure 1). The model combined a decision tree for the first 90 days after acute ischemic stroke and the Markov model for those at risk after 3 months. The Markov model consisted of 3 mutually exclusive health states, functional independence (modified Rankin Scale [measurement of degree of disability] $=0-2$ ), disability (modified Rankin Scale $=3-5$ ) and death (modified Rankin Scale $=6$ ). Target patients received treatment with mechanical thrombectomy plus intravenous thrombolysis or intravenous thrombolysis alone, and they would be either functionally independent, disabled or dead at 90 days after acute ischemic stroke. Survivors at 90 days would join the corresponding health state in the Markov model. Patients could transfer between health states or stay in the same health states at the end of each monthly cycle, with assigned probabilities. In the model, patients could recover from disability to functional independence during the first year after a stroke but not after the first year.

\section{Principal assumptions}

The following assumptions were made for the base case analysis:

- Compared with treatment with intravenous thrombolysis alone, mechanical thrombectomy plus intravenous thrombolysis treatment can reduce the risk of disability at 90 days but not mortality, ${ }^{15}$ because only 1 of the 5 RCTs showed a reduction in mortality. ${ }^{14}$

- Patients' long-term health outcomes (i.e., more than 3 mo after a major stroke) would be conditional on their health status at 90 days (i.e., functional independence or disability).

- Disability was associated with increased risk of mortality and reduced health-related quality of life. ${ }^{19}$

- The two treatments were associated with a similar risk of symptomatic intracerebral hemorrhage within 90 days after stroke. ${ }^{15}$ We ignored it in the model because it would not impact the incremental cost-effectiveness ratio.

\section{Model input parameters}

Data were obtained from the best available evidence (Table 1 and Table 2). When necessary, we contacted authors to clarify questions we had regarding their publications. When we could not obtain the desired estimates, we adapted available data after discussion with clinical experts. We also consulted experts to validate our parameter estimates.

\section{Intervention summary estimates (the first $90 \mathrm{~d}$ )}

We conducted a meta-analysis to estimate the proportion of functional independence and mortality in the intravenous thrombolysis only arm at 90 days, and estimated these parameters for the mechanical thrombectomy plus intravenous thrombolysis arm at the given odds ratio (OR) from metaanalysis. ${ }^{15}$ The pooled estimate of the adjusted $\beta$ coefficient in the linear regression in 2 of the $5 \mathrm{RCTs}^{10,12}$ showed that treatment with mechanical thrombectomy plus intravenous thrombolysis increased EuroQol five dimensions questionnaire (EQ-5D) utility by 0.074 (95\% confidence interval [CI] $0.014-0.133)$ at 90 days compared with treatment with intravenous thrombolysis alone. We assumed that the two arms 
had the same utility at base, but the difference in utility linearly increased over time reaching 0.074 at 90 days after stroke. As a result, the mechanical thrombectomy arm would lead to a quality-adjusted life years (QALY) gain of 0.008 in the first 90 days, i.e., $\{[(0+$ utility increase at 90 days $) / 2] \times$ $0.25\} \times(1-$ probability of death in 90 days $)$.

\section{Natural history (3 mo after stroke)}

The evidence for long-term outcomes for acute ischemic stroke is sparse in Canada. For our model inputs, we used evidence from the Oxford Vascular Study, involving a large cohort study in the UK. ${ }^{17,18}$ We calibrated the parameters for the Markov model using a 7-step approach introduced by Vanni and colleagues. ${ }^{33}$ We summarize the calibration process in Figure 2 (more details in Appendix 1, available at www.cmajopen.ca/ content/4/2/E316/suppl/DC1). We defined the parameters for estimating time-dependent transition probabilities and selected the proportions of mortality, functional independence and disability at 6 months and 1,2 and 5 years in the moderate stroke group of the Oxford Vascular Study as the calibration targets. ${ }^{17,18} \mathrm{We}$ used a grid search to obtain plausible ranges for each parameter and then simulated 1000000 parameter sets by sampling values from the plausible ranges. We assessed the goodness of fit (i.e., absolute deviation and sum of squared errors) for the model output produced by each parameter set. The best fitting parameter set (i.e., minimal sum of squared errors) was used as the base case, and 1000 parameter sets were randomly selected from those meeting the acceptance criteria for probabilistic sensitivity analysis.

\section{Costs}

Costs for stroke were based on the Economic Burden of Ischemic Stroke study ${ }^{29}$ and are expressed in April 2015 Canadian dollars. ${ }^{34}$ The Economic Burden of Ischemic Stroke study was a prospective cohort study involving patients with ischemic stroke in 12 Canadian stroke centres. The authors stratified the costs for disability status (modified Rankin Scale $=0-2$ and modified Rankin Scale $=3-5$ ) measured at discharge. They also divided costs into direct (e.g., emergency services, hospitalization, rehabilitation, physician services, diagnostics, medications) and indirect (e.g., productivity loss and resource use for unpaid caregivers) costs. We considered direct costs from the Economic Burden of Ischemic Stroke study ${ }^{29}$ in the base case analysis. We did not include stroke recurrence as a separate event in our model, but the health care costs of recurrence were accounted for in the cost estimates.

It is difficult to make a precise estimate of the additional cost of mechanical thrombectomy plus intravenous thrombolysis intervention relative to intravenous thrombolysis; apart from the materials and staffing, mechanical thrombectomy may also impact intensive care unit time, angiography suite time, diagnostics, physician time and rehabilitation. According to the published health economic studies of mechanical thrombectomy (with or without intravenous thrombolysis) versus intravenous thrombolysis (or best medical treatment), the extra cost of mechanical thrombectomy treatment versus control in most studies ranged from $\$ 10000$ to $\$ 20000 .^{23-29}$ (Appendix 2, available at www.cmajopen.ca/content/4/2/

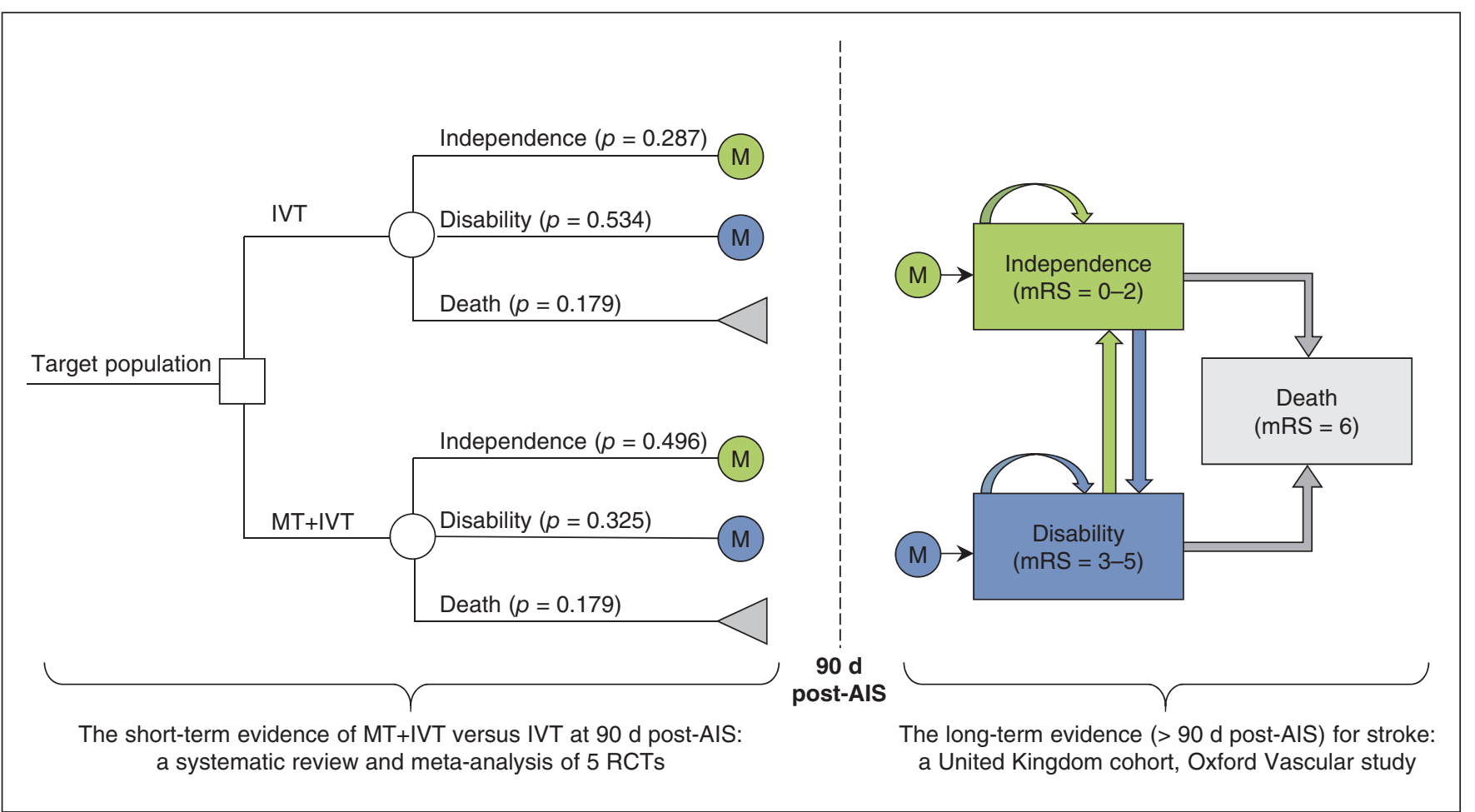

Figure 1: Decision analytic model of mechanical thrombectomy plus intravenous thrombolysis versus intravenous thrombolysis alone for acute ischemic stroke. AIS = acute ischemic stroke, IVT = intravenous thrombolysis, $\mathrm{M}=$ Markov model, $\mathrm{mRS}=$ modified Rankin Scale, MT = mechanical thrombectomy, RCT = randomized controlled trial. 
E316/suppl/DC1). We estimated that the additional cost of mechanical thrombectomy treatment in Ontario lies somewhere in the middle at $\$ 15000$.

\section{Health utilities}

Several different factors significantly affect the health utility of stroke patients, including stroke severity, comorbidity and age. ${ }^{18}$ For simplicity, we used the EQ-5D utilities found in an article by Dorman and colleagues, which only considered the stroke severity of functional independence and disability. ${ }^{30}$

\section{Statistical analysis}

Using our Markov decision process analytic model, we compared the cost-effectiveness of the 2 treatment strategies. Our main outcome was the incremental cost-effectiveness ratio, measured as incremental cost per QALY gained. Because there are considerable uncertainties of long-term outcomes for both treatment strategies, we selected a 5-year time horizon as the base case scenario. An annual discount rate of 5\% was applied to both costs and QALYs.

We conducted a scenario analysis using inputs from the Endovascular Treatment for Small Core and Proximal Occulsion Ischemic Stroke (ESCAPE) trial. ${ }^{14}$ Eleven health centres in Canada participated in this trial. This study included patients with proximal occlusions and contraindications to intravenous tissue plasminogen activator, representing $25 \%$ of the trial participants and the group of patients who may obtain the most benefit from mechanical thrombectomy treatment. We also analyzed the scenario involving stroke patients with severe neurologic deficit (National Institutes of Health Stroke Scale score, $\geq 20$ ) based on pooled results from the Interventional Management of Stroke III and Multicenter Randomized Clinical Trial of Endovascular Therapy for Acute Ischemic Stroke (Netherlands) trials. ${ }^{31}$

\begin{tabular}{|c|c|c|c|}
\hline Description & Mean $(95 \% \mathrm{Cl})$ & $\begin{array}{l}\text { Distribution (parameter 1, parameter 2) } \\
\text { for PSA }\end{array}$ & Reference \\
\hline \multicolumn{4}{|l|}{ Efficacy of treatment at $90 \mathrm{~d}$ post-AIS } \\
\hline \multicolumn{4}{|l|}{ IVT alone strategy, \% } \\
\hline All-cause mortality & $17.86(13.89-21.82)$ & $\beta(64.03,294.50)$ & $10-14$ \\
\hline Functional independence & $28.74(21.80-35.67)$ & $\beta(46.68,115.75)$ & $10-14$ \\
\hline \multicolumn{4}{|l|}{ MT plus IVT strategy } \\
\hline All-cause mortality, \% & $17.86(13.89-21.82)$ & $\beta(64.03,294.50)$ & 10-14 \\
\hline $\begin{array}{l}\text { Odds ratio of functional independence, MT plus IVT v. IVT } \\
\text { alone* }\end{array}$ & $2.39(1.88-3.04)$ & Log-normal $(0.8713,0.1226)$ & 10-14 \\
\hline Difference in health utility relative to IVT & $0.0735(0.0137-0.1333)$ & Normal $(0.0735,0.0305)$ & 10,12 \\
\hline $\begin{array}{l}\text { Calibrated monthly transition probabilities of natural } \\
\text { history for }>3 \mathrm{mo} \text { after stroke }\end{array}$ & $\begin{array}{l}\text { Best fitting parameter } \\
\text { set }\end{array}$ & 1000 convergent parameter sets & \\
\hline \multicolumn{4}{|l|}{ From functional independence to disability, mo } \\
\hline $4-6$ & 0.0321 & - & $17,18,20,21$ \\
\hline $7-12$ & 0.0220 & - & $17,18,20,21$ \\
\hline $13-24$ & 0.0134 & - & $17,18,20,21$ \\
\hline 25-36 & 0.0111 & - & $17,18,20,21$ \\
\hline $37-48$ & 0.0093 & - & $17,18,20,21$ \\
\hline $49-60$ & 0.0077 & - & $17,18,20,21$ \\
\hline \multicolumn{4}{|l|}{ From disability to functional independence, mo } \\
\hline $4-6$ & 0.0372 & - & 20 \\
\hline $7-12$ & 0.0156 & - & 20 \\
\hline $13-60$ & 0 & - & Assumption $* \star$ \\
\hline \multicolumn{4}{|l|}{ From functional independence to death, mo } \\
\hline $4-12$ & 0.0080 & - & $17,18,20,21$ \\
\hline $13-24$ & 0.0034 & - & $17,18,20,21$ \\
\hline $25-36$ & 0.0039 & - & $17,18,20,21$ \\
\hline $37-48$ & 0.0043 & - & $17,18,20,21$ \\
\hline $49-60$ & 0.0047 & - & $17,18,20,21$ \\
\hline
\end{tabular}




\section{OPEN}

Research

We also conducted 1- and multi-way sensitivity analyses to assess factors that affect the incremental cost per QALY gained. Given no significant differences in functional independence were found among subgroups of status of intravenous thrombolysis $(p=0.72)$ and occlusion site $(p=0.94)$, the analyses for those subgroups were not conducted. Additionally, we conducted probabilistic sensitivity analysis by assigning probability distributions to model parameters ( $N$ iterations $=1000)$. Distributions of inputs are listed in Table 1 and Table 2 .

We conducted the economic analyses and calibration using SAS version 9.4 (SAS Institute Inc.). We also used $\mathrm{R}$ version 3.1.2 (R Development Core Team, Vienna, Austria) for metaanalysis (metafor package in R) and simultaneous CI for multinomial proportion (MultinomialCI package in $\mathrm{R}$, available at http://CRAN.R-project.org/package=MultinomialCI; and Coin MinD package in R, available at http:/CRAN.R-project.org/ package=CoinMinD). The model validation can be found in Appendix 3, available at www.cmajopen.ca/content/4/2/E316/ suppl/DC1.

\section{Results}

\section{Base case and scenario analyses}

Based on the model proposed in Figure 1 and using the parameter estimates given in Table 1 and Table 2, the mechanical thrombectomy plus intravenous thrombolysis strategy was associated with an incremental cost-effectiveness ratio of $\$ 11990$ per QALY gained over 5 years compared with intravenous thrombolysis alone in the base case (Table 3). Compared with the base case, inputs from the ESCAPE Trial resulted in greater QALYs gained (0.348 QALYs) with higher incremental cost (\$9324), corresponding to an incremental cost-effectiveness ratio of \$26815 per QALY gained. Although there is no universally accepted maximum willingness-to-pay threshold in Canada, the mechanical thrombectomy plus intravenous thrombolysis strategy is highly likely to be cost-effective if the willingness-to-pay threshold were \$50 000 per QALY or higher. For patients with severe stroke, assuming no improvement in mortality, the incremental cost-effectiveness ratio was increased to $\$ 81651$ with QALY gained of 0.106 and an incremental cost of $\$ 8691$.

Table 1 (part 2 of 2): Model inputs for base case

\begin{tabular}{|c|c|c|c|}
\hline Description & Mean $(95 \% \mathrm{Cl})$ & $\begin{array}{l}\text { (parameter } 1, \text { par } \\
\text { for PSA }\end{array}$ & Reference \\
\hline \multicolumn{4}{|l|}{ From disability to death, mo } \\
\hline $4-12$ & 0.0229 & - & $17,18,20,21$ \\
\hline $13-24$ & 0.0096 & - & $17,18,20,21$ \\
\hline 25-36 & 0.0108 & - & $17,18,20,21$ \\
\hline $37-48$ & 0.0122 & - & $17,18,20,21$ \\
\hline $49-60$ & 0.0131 & - & $17,18,20,21$ \\
\hline \multicolumn{4}{|l|}{ Health care costs, \$CAD† } \\
\hline \multicolumn{4}{|l|}{ First 3 mo after stroke } \\
\hline Extra cost of MT treatment & 15000 & $\gamma(25,600)$ & $22-28$ \\
\hline Functional independence (mRS of 0-2) & 18852 & $\gamma(25,754.08)$ & 29 \\
\hline Disability (mRS of 3-6) & 57382 & $\gamma(25,2295.28)$ & 29 \\
\hline IVT alone, weighted by health status $\ddagger$ & 46308 & - & 22-29 \\
\hline MT + IVT, weighted by health status§ & 53471 & - & $22-29$ \\
\hline \multicolumn{4}{|l|}{ Greater than 3 mo after stroke } \\
\hline Functional independence (mRS of 0-2) & 1384 per month & $\gamma(25,55.36)$ & 29 \\
\hline Disability (mRS of 3-5) & 3080 per month & $\gamma(25,123.2)$ & 29 \\
\hline \multicolumn{4}{|l|}{ Health utility for $>3 \mathrm{mo}$ after stroke } \\
\hline Functional independence (mRS of 0-2) & $0.71(0.68-0.74)$ & $\beta(623.29,254.58)$ & 30 \\
\hline Disability (mRS of 3-5) & $0.31(0.29-0.34)$ & $\beta(407.26,906.49)$ & 30 \\
\hline $\begin{array}{l}\text { Note: AIS = acute ischemic stroke, } \$ C A D=\text { Canadian doll } \\
\text { PSA = probabilistic sensitivity analysis. } \\
\text { *Given the odds ratio of } 2.39 \text { and pooled proportion of fun } \\
+ \text { tEconomic Burden of Ischemic Stroke study }{ }^{29} \text { did not rep } \\
\text { sensitivity analysis. } \\
\neq \$ 18852 \times 0.2874+\$ 57382 \times 0.7126=\$ 46308 \text {. } \\
\$ \$ 15000+\$ 18852 \times 0.4908+\$ 57382 \times 0.5092=\$ 534 \\
\text { TUnless stated otherwise. } \\
\text { **Evidence suggests that the chance of patients recoverin }\end{array}$ & $\begin{array}{l}\text { erval, IVT = intravenous } \\
\text { we estimated that the p } \\
\text { (SE) of their cost estima }\end{array}$ & $\begin{array}{l}\text { modified Rankin Scale, M } \\
\text { independence was } 0.490 \\
\text { SE was equal to } 20 \% \text { of t }\end{array}$ & rombectomy, \\
\hline
\end{tabular}




\section{Deterministic sensitivity analysis}

We examined several factors that could affect the incremental cost-effectiveness ratio of mechanical thrombectomy plus intravenous thrombolysis versus intravenous thrombolysis alone (Table 4). When the model inputs were varied, the mechanical thrombectomy plus intravenous thrombolysis approach remained cost-effective in most scenarios. The main factors influencing incremental cost-effectiveness ratio were time horizon, additional cost of mechanical thrombectomy and age. The incremental cost-effectiveness ratio decreased, with longer follow-up time in the first 4 years (Appendix 4, available at www.cmajopen.ca/content/4/2/E316/suppl/DC1), and was relatively stable at about $\$ 10000$ per QALY gained at a followup of 5 years or longer.

\section{Probabilistic sensitivity analysis}

Results of the Monte Carlo simulations were consistent with those in the base case (Figure 3). The probability of mechanical thrombectomy plus intravenous thrombolysis dominating intravenous thrombolysis alone (i.e., mechanical thrombec- tomy plus intravenous thrombolysis with lower costs and higher QALYs) was 0.286. The cost-effectiveness acceptability curve showed that the probability of mechanical thrombectomy plus intravenous thrombolysis being cost-effective was $57.5 \%, 89.7 \%$ and $99.6 \%$, respectively, at thresholds of $\$ 20000, \$ 50000$, and \$100 000 per QALY gained, respectively (Appendix 5, available at www.cmajopen.ca/content/4/2/ E316/suppl/DC1).

\section{Interpretation}

Our economic analysis showed that mechanical thrombectomy is highly likely to be cost-effective according to commonly cited cost-effectiveness thresholds. This is concordant with the large clinical effect size observed in the randomized trials, and sensitivity analyses suggested that these findings are robust to a range of assumptions.

Our findings were consistent with the most recent published economic evaluation from the United States, ${ }^{22}$ which evaluated new-generation devices and used efficacy estimates from a single

\begin{tabular}{|c|c|c|}
\hline Description & Mean & Reference \\
\hline \multicolumn{3}{|l|}{ Inputs from ESCAPE trial, efficacy of treatment at $90 \mathrm{~d}$ post AIS } \\
\hline \multicolumn{3}{|l|}{ IVT alone strategy, \% } \\
\hline All-cause mortality & 19.0 & 14 \\
\hline Functional independence & 29.3 & 14 \\
\hline Cost in first 3 mo, weighted by health status; \$CAD & 46093 & 14,29 \\
\hline \multicolumn{3}{|l|}{ MT + IVT strategy, \% } \\
\hline All-cause mortality & 10.4 & 14 \\
\hline Functional independence & 53.0 & 14 \\
\hline Cost in first 3 mo, weighted by health status; \$CAD & 51961 & 14,29 \\
\hline $\begin{array}{l}\text { Inputs from Broderick and colleagues, severe stroke } \\
\text { (National Institutes of Health Stroke Scale score } \geq 20 \text { ) }\end{array}$ & & 31 \\
\hline \multicolumn{3}{|l|}{ IVT alone strategy, \% } \\
\hline All-cause mortality & 34 & 31 \\
\hline Functional independence & 14 & 31 \\
\hline Cost in first $3 \mathrm{mo}$, weighted by health status; \$CAD & 51988 & 29,31 \\
\hline \multicolumn{3}{|l|}{ MT + IVT strategy } \\
\hline All-cause mortality, \% & 34 & Assumption* \\
\hline Odds ratio of functional independence, MT + IVT v. IVT alone & 1.97 & 31 \\
\hline Cost in first 3 mo, weighted by health status; $\$ C A D$ & 63026 & 29,31 \\
\hline \multicolumn{3}{|c|}{ Odds ratio of functional independence in subgroup patients, MT + IVT v. IVT; yr } \\
\hline$\leq 70$ & 3.02 & $10-14$ \\
\hline$>70$ & 1.79 & 10-14 \\
\hline \multicolumn{3}{|l|}{ Including cost for cost of end-of-life care } \\
\hline Cost of end-of-life care for death after 90 d poststroke; \$CAD & 50892 & 32 \\
\hline \multicolumn{3}{|c|}{$\begin{array}{l}\text { Note: AIS = acute ischemic stroke, } \$ C A D=\text { Canadian dollars in } 2015, \text { IVT }=\text { intravenous thrombolysis, } \mathrm{mRS}=\text { modified Rankir } \\
\text { Scale, MT = mechanical thrombectomy. } \\
\text { 'This study did not find a significant difference in mortality between groups }(28.8 \% \mathrm{mRS} 6 \text { in the endovascular treatment } \\
\text { group v. } 34 \% \text { in the IT group). Therefore, we assumed no survival benefit for MT in this scenario analysis. }\end{array}$} \\
\hline
\end{tabular}


RCT. ${ }^{10}$ In that evaluation, mechanical thrombectomy (with or without intravenous thrombolysis) resulted in an incremental cost-effectiveness ratio of US\$14 137 per QALY gained.

We used the long-term outcome of a subgroup of patients in the Oxford Vascular Study ${ }^{17,18}$ in the UK to project the longterm outcomes of our target population in Canada. About $83 \%$ the patients in the UK cohort were patients with ischemic stroke. The treatments and age of patients were different between the cohort in the Oxford Vascular Study and the control arms in our model, but the disease severity in mortality (about 20\%) and disability rate (about $60 \%$ for survivors) at 90 days after stroke were similar. In addition, the UK and Canada have centrally planned and publicly funded health systems. We believe that it is reasonable to expect our target patients in Canada to have a similar trajectory to those in the UK.

\section{Strengths and limitations}

The strengths of our study include using high-quality evidence from the meta-analysis of 5 RCTs; ${ }^{15}$ using monthly compared with yearly cycles in the Markov model, which models disease progression more accurately; and the transitions from functional independence to disability, as well as from disability to functional independence (i.e., recovery), which models the progression of patients with stroke more naturally. Furthermore, we used a calibration approach to provide parameter estimates for the economic model, and experts validated model assumptions and inputs.

Our study also has several limitations that merit emphasis. First, the conclusions are limited by the short-interval followup (90 days) in the 5 RCTs identified, and the need to combine results with a cohort study to model longer-term outcomes.

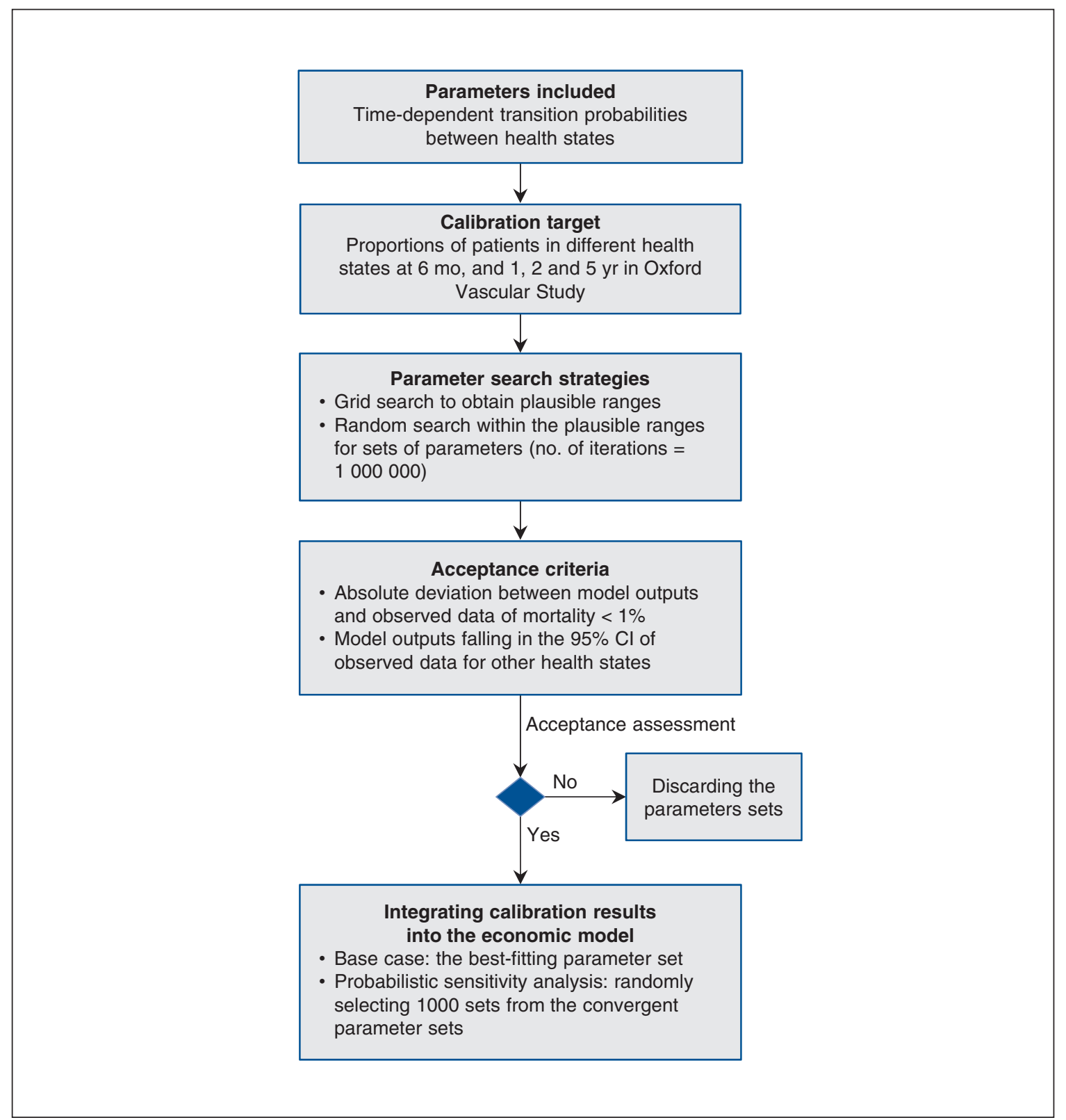

Figure 2: Flow chart of calibration for time-dependent transition probabilities. $\mathrm{Cl}=$ confidence interval. 


\begin{tabular}{|c|c|c|c|c|c|}
\hline Strategy & $\begin{array}{l}\text { Average total } \\
\text { costs (\$CAD) }\end{array}$ & $\begin{array}{l}\text { Incremental } \\
\text { cost }(\$ C A D)\end{array}$ & QALY & $\begin{array}{l}\text { QALYS } \\
\text { gained }\end{array}$ & $\begin{array}{l}\text { ICER* } \\
\text { (\$CAD) }\end{array}$ \\
\hline \multicolumn{6}{|c|}{ Base case } \\
\hline IVT & 124419 & - & 1.273 & - & - \\
\hline MT + IVT & 126939 & 2520 & 1.484 & 0.210 & 11990 \\
\hline \multicolumn{6}{|c|}{ Efficacy based on ESCAPE trial14 } \\
\hline IVT & 122901 & - & 1.265 & - & - \\
\hline MT + IVT & 132224 & 9323 & 1.613 & 0.348 & 26815 \\
\hline \multicolumn{6}{|c|}{ Severe stroke } \\
\hline IVT & 116826 & - & 0.933 & - & - \\
\hline MT + IVT & 125517 & 8691 & 1.039 & 0.106 & 81651 \\
\hline \multicolumn{6}{|c|}{$\begin{array}{l}\text { Note: Numbers may appear inexact because of rounding. } \$ C A D=\text { Canadian dollars in } 2015, \text { ICER }= \\
\text { incremental cost-effectiveness ratio, IVT = intravenous thrombolysis, MT = mechanical thrombectomy, } \\
\text { QALY = quality-adjusted life-year. } \\
\text { *Incremental cost per QALY gained. }\end{array}$} \\
\hline
\end{tabular}

\begin{tabular}{|c|c|}
\hline Scenario & $\begin{array}{l}\text { Incremental cost per } \\
\text { QALY gained (\$CAD) }\end{array}$ \\
\hline Base case analysis (reference) & 11990 \\
\hline \multicolumn{2}{|l|}{ Time horizon, yr } \\
\hline 1 & 91080 \\
\hline 3 & 20540 \\
\hline 10 & 11491 \\
\hline $15^{*}$ & 12877 \\
\hline $\begin{array}{l}\text { MT with reduced mortality risk (odds ratio of mortality, MT + } \\
\text { IVT v. IVT alone, 0.80) }\end{array}$ & 22891 \\
\hline \multicolumn{2}{|l|}{ Extra cost of MT treatment, \$CAD } \\
\hline 10000 & Dominant \\
\hline 20000 & 35779 \\
\hline \multicolumn{2}{|l|}{ Age group, yr } \\
\hline$\leq 70$ & 4429 \\
\hline$>70$ & 29899 \\
\hline \multicolumn{2}{|l|}{ Health utility in functional independence and disability states } \\
\hline Lower limit of $95 \% \mathrm{Cl}$ & 12366 \\
\hline Upper limit of $95 \% \mathrm{Cl}$ & 11809 \\
\hline \multicolumn{2}{|l|}{ Annual discount rate for both cost and utility, \% } \\
\hline 0 & 10028 \\
\hline 3 & 11205 \\
\hline 10 & 13943 \\
\hline $\begin{array}{l}\text { Including cost for end-of-life care for those who survive at } 90 \mathrm{~d} \\
\text { after an acute ischemic stroke }\end{array}$ & 4212 \\
\hline \multicolumn{2}{|c|}{$\begin{array}{l}\text { Note: } \$ C A D=\text { Canadian dollars in } 2015, \mathrm{Cl}=\text { confidence interval, IVT = intravenous thrombolysis, MT = } \\
\text { mechanical thrombectomy, QALY = quality-adjusted life-year. } \\
{ }^{*} \text { About } 5.4 \% \text { and } 6.9 \% \text { of patients were alive in the IVT alone and IVT + MT arms, respectively, at } 15 \mathrm{yr} \\
\text { follow-up in our model. }\end{array}$} \\
\hline
\end{tabular}




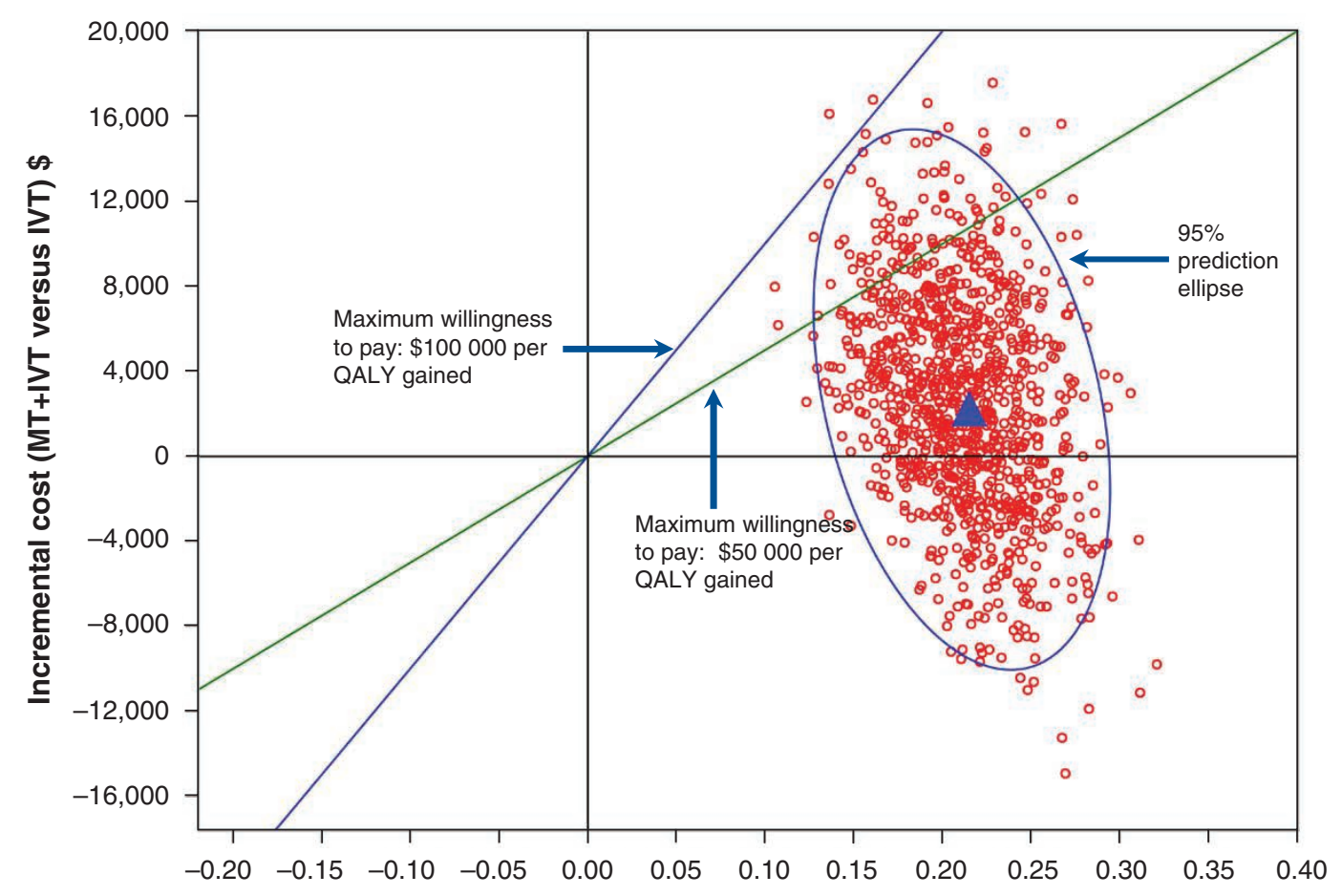

Incremental QALY (MT+IVT versus IVT)

Figure 3: Cost-effectiveness plane: the incremental cost and QALY gained of mechanical thrombectomy plus intravenous thrombolysis versus intravenous thrombolysis alone. The blue triangle in the centre of the circle indicates the base case scenario. Each red circle surrounding the blue triangle represents a single result from the simulation, presenting the incremental effects and incremental costs of mechanical thrombectomy plus intravenous thrombolysis compared with intravenous thrombolysis alone. IVT = intravenous thrombosis, MT = mechanical thrombectomy, QALY = quality-adjusted life-year.

Second, many of our parameter estimates came from studies conducted outside Ontario; parameter estimates may have been different if data from Ontario were available. However, our findings were robust to a range of plausible assumptions. Third, we caution that we did not model specific endovascular devices or patient imaging-selection strategies, and cost-effectiveness may be influenced by these choices, as well as by costs incurred by system-level changes implemented to change stroke care. In addition, future RCTs that examine long-term outcomes in patients with stroke would help validate several important parameters in our model.

\section{Conclusion}

Treatment with mechanical thrombectomy as an adjunct therapy to intravenous thrombolysis is cost-effective compared with intravenous thrombolysis alone in patients with acute large-artery ischemic stroke. In publicly funded health care systems such as Canada's, the use of mechanical thrombectomy is likely to represent good value for money and should be supported.

\section{References}

1. van der Worp HB, van Gijn J. Clinical practice. Acute ischemic stroke. N Engl $\mathcal{Z}$ Med 2007;357:572-9.
2. Access to stroke care: the critical first hours. Ottawa: Heart and Stroke Foundation of Canada; 2016. Available: http://www.heartandstroke.com /atf/cf/\%7B99452d8b-e7f1-4bd6-a57d-b136ce6c95bf\%7D/HSF_2015_STROKE_ REPORT_FINAL.pdf (accessed 2016 Apr. 28).

3. Statistics. Ottawa: Heart and Stroke Foundation of Canada; 2016. Available: http:// www.heartandstroke.com/site/c.ikIQLcMWJtE/b.3483991/k.34A8/Statistics.htm (accessed 2016 Apr. 28).

4. Types of stroke - ischemic strokes (clots). Dallas: American Heart Association; 2015. Available: www.strokeassociation.org/STROKEORG/AboutStroke/Typesof Stroke/IschemicClots/Ischemic-Strokes-Clots_UCM_310939_Article.jsp (accessed 2015 Nov. 3).

5. Jauch EC, Saver JL, Adams HP, et al. Guidelines for the early management of patients with acute ischemic stroke: a guideline for healthcare professionals from the American Heart Association/American Stroke Association. Stroke 2013;44:870-947.

6. Emberson J, Lees KR, Lyden P, et al. Effect of treatment delay, age, and stroke severity on the effects of intravenous thrombolysis with alteplase for acute ischaemic stroke: a meta-analysis of individual patient data from randomised trials. Lancet 2014;384:1929-35.

7. Broderick JP, Palesch YY, Demchuk AM, et al. Endovascular therapy after intravenous t-PA versus t-PA alone for stroke. N Engl 7 Med 2013;368:893-903.

8. Ciccone A, Valvassori L, Nichelatti M, et al. Endovascular treatment for acute ischemic stroke. NEngl 7 Med 2013;368:904-13.

9. Kidwell CS, Jahan R, Gornbein J, et al. A trial of imaging selection and endovascular treatment for ischemic stroke. N Engl 7 Med 2013;368:914-23.

10. Berkhemer OA, Fransen PS, Beumer D, et al. A randomized trial of intra-arterial treatment for acute ischemic stroke. N Engl f Med 2015;372:11-20.

11. Saver JL, Goyal M, Bonafe A, et al. Stent-retriever thrombectomy after intravenous t-PA vs. t-PA alone in stroke. N Engl f Med 2015;372:2285-95.

12. Jovin TG, Chamorro A, Cobo E, et al. Thrombectomy within 8 hours after symptom onset in ischemic stroke. N Engl 7 Med 2015;372:2296-306.

13. Campbell BC, Mitchell PJ, Kleinig TJ, et al. Endovascular therapy for ischemic stroke with perfusion-imaging selection. N Engl F Med 2015;372:1009-18.

14. Goyal M, Demchuk AM, Menon BK, et al. Randomized assessment of rapid endovascular treatment of ischemic stroke. N Engl F Med 2015;372:1019-30. 
15. Mechanical thrombectomy in patients with acute ischemic stroke: a health technology assessment. Toronto: Health Quality Ontario; 2015. Available: www.hqontario. ca/Portals/0/Documents/evidence/reports/hta-mechanical-thrombectomy-1602-en.pdf (accessed 2016 Apr. 20).

16. Casaubon LK, Boulanger JM, Blacquiere D, et al. Canadian Stroke Best Practice Recommendations: Hyperacute Stroke Care guidelines, update 2015. Int 7 Stroke 2015;10:924-40.

17. Luengo-Fernandez R, Paul NL, Gray AM, et al. Population-based study of disability and institutionalization after transient ischemic attack and stroke: 10-year results of the Oxford Vascular Study. Stroke 2013;44:2854-61.

18. Luengo-Fernandez R, Gray AM, Bull L, et al. Quality of life after TIA and stroke: ten-year results of the Oxford Vascular Study. Neurology 2013;81:1588-95.

19. Hankey GJ. Long-term outcome after ischaemic stroke/transient ischaemic attack. Cerebrovasc Dis 2003;16(Suppl 1):14-9.

20. Hankey GJ, Spiesser J, Hakimi Z, et al. Rate, degree, and predictors of recovery from disability following ischemic stroke. Neurology 2007;68:1583-7.

21. The human mortality database. Life tables in 2004 in the United Kingdom. Berkeley: The Human Mortality Database Research Teams; 2013. Available: www.mortality.org/ (accessed 2015 Jun. 1)

22. Leppert MH, Campbell JD, Simpson JR, et al. Cost-effectiveness of intra-arterial treatment as an adjunct to intravenous tissue-type plasminogen activator for acute ischemic stroke. Stroke 2015;46:1870-6.

23. Rai AT, Evans K. Hospital-based financial analysis of endovascular therapy and intravenous thrombolysis for large vessel acute ischemic strokes: the 'bottom line.' 7 Neurointerv Surg 2015;7:150-6.

24. Simpson KN, Simpson AN, Mauldin PD, et al. Drivers of costs associated with reperfusion therapy in acute stroke: The Interventional Management of Stroke III trial. Stroke 2014;45:1791-8.

25. Chen M. Cost-effectiveness of endovascular therapy for acute ischemic stroke. Neurology 2012;79:S16-21.

26. Nguyen-Huynh MN, Johnston SC. Is mechanical clot removal or disruption a costeffective treatment for acute stroke? A7NR Am 7 Neuroradiol 2011;32:244-9.

27. Kim AS, Nguyen-Huynh M, Johnston SC. A cost-utility analysis of mechanical thrombectomy as an adjunct to intravenous tissue-type plasminogen activator for acute large-vessel ischemic stroke. Stroke 2011;42:2013-8.

28. Patil CG, Long EF, Lansberg MG. Cost-effectiveness analysis of mechanical thrombectomy in acute ischemic stroke. 7 Neurosurg 2009;110:508-13.

29. Mittmann N, Seung SJ, Hill MD, et al. Impact of disability status on ischemic stroke costs in Canada in the first year. Can 7 Neurol Sci 2012;39:793-800.

30. Dorman P, Dennis M, Sandercock P. Are the modified "simple questions" a valid and reliable measure of health related quality of life after stroke? United Kingdom Collaborators in the International Stroke Trial. 7 Neurol Neurosurg Psychiatry 2000;69:487-93.

31. Broderick JP, Berkhemer OA, Palesch YY, et al. Endovascular therapy is effective and safe for patients with severe ischemic stroke: pooled analysis of interventional management of stroke III and multicenter randomized clinical trial of endovascular therapy for acute ischemic stroke in the Netherlands data. Stroke 2015;46:3416-22.

32. Pham B, Krahn M. End-of-life care interventions: an economic analysis. Ont Health Technol Assess Ser 2014;14:1-70.

33. Vanni T, Karnon J, Madan J, et al. Calibrating models in economic evaluation: a seven-step approach. Pharmacoeconomics 2011;29:35-49.

34. Consumer Price Index, health and personal care, by province (monthly). Ottawa: Statistics Canada; 2015. Available: www.statcan.gc.ca (accessed 2015 June 1).
35. Viechtbauer W. Conducting meta-analyses in $\mathrm{R}$ with the metafor package. I Stat Softw 2010;36:1-48.

Affiliations: Health Quality Ontario (Xie, Lambrinos, Chan, Dhalla, Sikich); Toronto Health Economics and Technology Assessment Collaborative (Xie), Leslie Dan Pharmacy, University of Toronto; Departments of Medical Imaging and Surgery (Krings, Pereira), University of Toronto; University Health Network - Toronto Western Hospital (Krings, Casaubon); Department of Medicine (Casaubon), Division of Neurology, University of Toronto; Stroke Outcomes Research Centre (Saposnik), St. Michael's Hospital, University of Toronto; Division of Neuroradiology (Bharatha), Department of Medical Imaging, St. Michael's Hospital, University of Toronto; Ontario Stroke Network (O'Callaghan, Kelloway), Toronto, Ont.; Ottawa Hospital Research Institute and Diagnostic Imaging - Interventional Neuroradiology (Lum), The Ottawa Hospital, University of Ottawa; Division of Neurology (Stotts), The Ottawa Hospital, Ottawa, Ont.; Department of Clinical Neurosciences (Hill), Hotchkiss Brain Institute, Cumming School of Medicine, University of Calgary, Calgary, Alta.

Contributors: This economic evaluation was part of a Health Technology Assessment from Health Quality Ontario. Irfan Dhalla and Nancy Sikich conceived and supervised the study. Xuanqian Xie developed the economic model and conducted the statistical analyses. Xuanqian Xie and Anna Lambrinos drafted the article. All of the authors contributed substantially to study design and interpretation of data, revised the article critically for important intellectual content, gave final approval of the version to be published and agreed to act as guarantors of the work.

Competing interests: Xuanqian Xie, Anna Lambrinos, Brian Chan, Irfan Dhalla and Nancy Sikich receive a personal salary from Health Quality Ontario. Leanne Casaubon received consultant fees from Medtronic Canada, speaker fees from Bayer and compensation as a member of the Advisory Board of Covidien Canada. Aditya Baratha received a grant from the ESCAPE trial (University of Calgary). Michael Hill received compensation from Merck; in-kind nonfinancial support from Hoffmann-La Roche Canada Ltd.; grants from Covidien Canada (ESCAPE trial), Alberta Innovates Health Solutions, Canadian Institutes of Health Research, Heart \& Stroke Foundation of Canada and National Institute of Neurological Disorders and Stroke; he has a patent pending with the US Patent Office (no. 62/086,077) and he owns stock in Calgary Scientific Incorporated (medical imaging software).

Disclaimer: The views and opinions expressed by the authors in this publication are those of the authors and do not necessarily reflect those of Health Quality Ontario.

Supplemental information: For reviewer comments and the original submission of this manuscript, please see www.cmajopen.ca/content/4/2/ E316/suppl/DC1 